\title{
High-dose vitamin C supplement use is associated with self-reported histories of breast cancer and other illnesses in the UK Women's Cohort Study
}

\author{
Jayne Hutchinson ${ }^{1 * *}$, Victoria J Burley ${ }^{1}$, Darren C Greenwood ${ }^{2}$, James D Thomas ${ }^{1}$ and \\ Janet E Cade ${ }^{1}$ \\ ${ }^{1}$ Nutritional Epidemiology Group, School of Food Science and Nutrition, University of Leeds, Willow Terrace \\ Road, Leeds LS2 9JT, UK: ${ }^{2}$ Biostatistics Unit, Level 8, Worsley Building, University of Leeds, Leeds, UK
}

Submitted 14 March 2010: Accepted 3 September 2010: First published online 29 October 2010

\begin{abstract}
Objective: To determine whether frequent vitamin C supplement use is associated with healthier behaviours, and a history of cancer and other illnesses in UK women. Design: The present cross-sectional analysis examines the odds of taking supplements containing vitamin $\mathrm{C}$ as recorded in $4 \mathrm{~d}$ food diaries, based on lifestyle characteristics and morbidity history self-reported by questionnaire.

Setting: A large national UK cohort study.

Subjects: A total of 12453 women aged between 37 and 79 years.

Results: Women frequently taking supplements containing vitamin C, compared to those who did not, had healthier behaviours, including higher consumption of fruit and vegetables. Frequent high-dose vitamin C users $(\geq 1000 \mathrm{mg}$ ) had a higher socio-economic status, visited alternative practitioners more often than family or private doctors, and were more likely to be ex-smokers and to drink little or no alcohol. Women who self-reported having had cancer (OR $=1 \cdot 33$, 95\% CI $1 \cdot 00$, $1 \cdot 76)$ or specifically breast cancer $(\mathrm{OR}=1 \cdot 70,95 \% \mathrm{CI} 1 \cdot 14,2 \cdot 55)$, or reported a family history of cancer $(\mathrm{OR}=1 \cdot 16,95 \% \mathrm{CI} 0 \cdot 95,1 \cdot 41)$ or breast cancer $(\mathrm{OR}=1 \cdot 26$, $95 \%$ CI 1.01, 1.58) had increased odds of being frequent high-dose users after adjusting for sociodemographic and health behaviours. Women with personal or family histories of some cardiovascular or intestinal disorders were more likely to take supplements containing vitamin $\mathrm{C}$, though not necessarily at high doses.

Conclusions: High-dose vitamin C intake by UK women was associated with healthier behaviours and a history of breast cancer, total cancer and other illnesses. Consequences of high-dose vitamin $\mathrm{C}$ supplement intake are not clear at the population level.
\end{abstract}

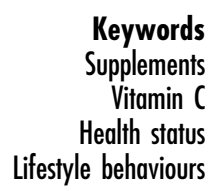

Keywords

Vitamin C Lifestyle behaviours
Despite lack of evidence of benefits ${ }^{(1,2)}$, the intake of vitamin supplements reported by UK women increased from $17 \%$ in $1986-1987$ to $41 \%$ reported in $2008-2009^{(3,4)}$. A recent UK survey showed that users are most likely to be women aged $>55$ years and of higher socio-economic status ${ }^{(5)}$. An analysis of the UK Women's Cohort Study (UKWCS) found that users were significantly more likely to lead healthier lifestyles: to be more physically active; have a lower alcohol intake; a lower BMI; and eat diets that met the recommended dietary intake ${ }^{(6)}$. Therefore, they were less likely to need supplements than non-users ${ }^{(6)}$. Further support for this 'inverse supplement hypothesis' has been found in the $\mathrm{UK}^{(4,7,8)}$ and elsewhere ${ }^{(9-14)}$. Moreover, those classifying themselves as high-strength supplement users in a recent UK survey were particularly health conscious ${ }^{(5)}$.
Vitamin $\mathrm{C}$ is one of the most commonly used supplements in the $\mathrm{UK}^{(5,15)}$. However, suggestions that it is able to reduce the incidence of colds have been unsubstantiated in randomised controlled trials ${ }^{(16)}$. Furthermore, despite some clear evidence of an association between plasma vitamin $\mathrm{C}$ levels and reduced mortality from all causes, from CVD and from IHD $^{(17)}$, there is limited evidence to suggest that vitamin $\mathrm{C}$ supplement use is associated with reduced risk of CVD or mortality ${ }^{(2,18-20)}$.

Although general supplement use is particularly widespread in cancer survivors in the USA, with breast cancer survivors showing the highest use ${ }^{(21)}$, no overall association between vitamin C supplement intake $(\geq 150 \mathrm{mg}$ ) and prevalent cancer was found in the US Vitamins and Lifestyle (VITAL) cross-sectional study ${ }^{(22)}$. Furthermore, those with pre-existing diabetes, hypertension and CVD 
were less likely to use them ${ }^{(22)}$. However, a US study of women physicians showed those with pre-existing breast cancer were more likely to take vitamin C supplements than breast cancer-free women ${ }^{(10)}$.

UK health-conscious women with prevalent cancer were also more likely to take any supplement than cancerfree women ${ }^{(15)}$; however, other pre-existing chronic diseases have been inversely associated with the intake of vitamins, minerals or antioxidants in a UK study combining men and women ${ }^{(7)}$. To the best of our knowledge, no study has examined the relationship between the intake of vitamin C supplements in UK women and lifestyle factors or personal or family history of morbidities. The main aim of the present study was to determine whether women in the UKWCS who reported having had cancer or reported a relative who had cancer were more likely to use vitamin C supplements than those who did not report these histories. Further aims of the present study were to determine whether vitamin $C$ supplement use was associated with other morbidities and healthier behaviours.

\section{Methods}

UKWCS recruitment data were gathered between 1995 and 1998 from 35367 women who completed a 217-item $\mathrm{FFQ}^{(23-25)}$. This national cohort, which was designed to compare disease incidence in vegetarians, fish-eaters and meat-eaters, consisted of mainly Caucasian, well-educated, middle-class, middle-aged, married women who were recruited via the World Cancer Research Fund (WCRF) ${ }^{(23)}$. At recruitment, $62 \%$ of participants took some type of dietary supplement.

All the initial participants were re-contacted between 1999 and 2004, on average 4 years after recruitment; $12453(35 \%)$ completed a follow-up health and lifestyle questionnaire and a $4 \mathrm{~d}$ food diary. For each day, the diaries requested supplement brand, name, amount taken and dosage of any supplement taken. This information was matched against a database of supplement descriptions and ingredient compositions obtained from product labels provided by participants, suppliers' websites or provided directly by the manufacturers. The average daily intake of vitamin $\mathrm{C}$ contained in all supplement types was calculated for the total number of diary days on which vitamin $\mathrm{C}$ was taken.

Using the STATA statistical software package version 10.0 (StataCorp., College Station, TX, USA), univariable logistic regression was applied to the follow-up data to determine which participant characteristics predicted frequent supplement intake in two different classifications of users: those taking any dose of vitamin C (yes/no) and those taking high doses of vitamin C ( $\geq 1000 \mathrm{mg}$, yes/no). These users were compared to women not frequently taking 'any' or 'high' doses, respectively. The high dose of $1000 \mathrm{mg} / \mathrm{d}$ is the recommended safe upper limit; intake at this level and above has been linked to adverse effects, particularly gastrointestinal disturbance ${ }^{(26)}$. This level is $>15$ times of the recommended daily allowance (EU $\mathrm{RDA}=60 \mathrm{mg} / \mathrm{d}^{(27)}$ ) normally found in multivitamins. Frequent intake of supplements containing vitamin $\mathrm{C}$ in the present study was defined as taking on at least three out of the four diary days. This was compared to frequencies given in the follow-up questionnaire, completed concurrently with the diary. Respondents were asked to indicate which supplements and how often they were taken: more than once a day; daily; weekly; monthly; or less than once a month. The supplements listed included vitamin C, antioxidants, and multivitamins. Sociodemographic and health-related lifestyle variables that were significantly associated with either any dose or high intake were all included in a logistic regression model for mutual adjustment.

Social class and marital status variables were derived from answers to the questionnaire used at recruitment since this information was not provided at follow-up. The combined FFQ and health and lifestyle questionnaire used at recruitment was developed from the one used in the Oxford arm of the European Prospective Investigation into Cancer and Nutrition study ${ }^{(28)}$, which was validated on a subsample of 303 cohort participants ${ }^{(29)}$. All other variables were taken from responses to the follow-up questionnaire: BMI $\left(\mathrm{kg} / \mathrm{m}^{2}\right)$; smoking status; level of physical activity; parity; drinking alcohol less than once a week; red meat servings; total fruit and vegetable servings; and frequency of visits to doctors and alternative practitioners. Vigorous activity was defined as activity causing shortness of breath, rapid heart rate and sweating. Attendance at routine health checks was not significantly associated with vitamin $\mathrm{C}$ intake, and therefore was excluded from the models.

These variables, excluding visits to doctors and alternative practitioners, were used in logistic regression analyses to adjust the odds of women with a family or personal history of cancers and other health problems taking any or high doses ( $\geq 1000 \mathrm{mg}$ ) of vitamin C. Personal and family histories of breast cancer and total cancers were the principal analyses. For these and personal histories of the other cancers, additional analyses were performed at doses $\geq 250, \geq 500$ and $\geq 2000 \mathrm{mg}$. Given that vitamin C supplements are more likely to be taken in winter because well-publicised research had linked it to reduced duration of the seasonal common cold $^{(30)}$, sensitivity analyses were performed to assess the robustness of results to weighting the analyses by the inverse of the probability of being sampled in each season.

All information related to family or personal history of cancers and other illnesses was reported by the participants at follow-up. They were asked whether family members (blood relatives only) ever had medical conditions listed (see Table 4 for types provided) or ever had the following cancers: breast, skin, lung, colon and rectum, ovary, stomach, cervix, ovary, pancreas or prostate. The cancer history of first- and second-degree relatives 
was used to identify women potentially at raised or high risk of hereditary breast cancer. It was unknown whether affected relatives were on the same side of the family; therefore, this could only be approximate to the guidelines provided by the UK National Institute for Health and Clinical Excellence ${ }^{(31)}$. Participants were also asked to report their own history of disease, including whether they had previously been told they had a diagnosis of one of the cancers listed above.

\section{Results}

In all, 34\% ( $n$ 4242) of women frequently took supplements containing any dose of vitamin $\mathrm{C}$, on at least three of the four diary days, and 5\% ( $n$ 579) frequently took high doses of $\geq 1000 \mathrm{mg} ; 27 \%$ ( $n$ 1165) of those frequently taking any dose and 52\% ( $n$ 299) taking high doses of vitamin $\mathrm{C}$ took four or more types of supplements. Furthermore, $82 \%$ of users taking any dose and $86 \%$ of the high-dose users took some type of supplement at recruitment, on average 4 years earlier.

Substantial agreement $(\kappa=0 \cdot 70,95 \%$ CI $0 \cdot 68,0 \cdot 72)$ was found between answers relating to daily intake of vitamin $\mathrm{C}$, antioxidants or multivitamins in the questionnaire and 3 or $4 \mathrm{~d}$ of recorded intake of supplements containing any vitamin $\mathrm{C}$ dose in the $4 \mathrm{~d}$ diary. In addition, diary recording of doses $\geq 90 \mathrm{mg}$ taken at this frequency showed substantial agreement $(\kappa=0 \cdot 72,95 \%$ CI $0 \cdot 70,0.74)$ with questionnaire responses to daily vitamin C supplementation.

After mutual adjustment, significant lifestyle predictors of frequently taking supplements containing either high dose or any dose of vitamin $\mathrm{C}$ were eating more than five servings of fruit and vegetables per day; eating fewer servings of red meat; and visiting an alternative practitioner more often than women not frequently taking these supplements (Table 1). The odds of visiting an alternative practitioner four or more times in the past 12 months were substantially greater for high-dose takers compared to any dose takers $(\mathrm{OR}=2 \cdot 84,95 \% \mathrm{CI} 2 \cdot 20,3 \cdot 66 v$. OR $=$ $1 \cdot 75,95 \%$ CI $1 \cdot 51,2 \cdot 03)$. In addition, the odds of taking supplements containing any dose of vitamin C were significantly higher in women who exercised vigorously $>3$ times/week (OR $=1 \cdot 52,95 \%$ CI $1 \cdot 23,1 \cdot 8)$; or were aged $\geq 45$ years; of intermediate social class, divorced, childless, frequent visitors to their general practitioner or leaner. Significant predictors of frequent intake of high dose were being an ex-smoker when compared with never smokers $(\mathrm{OR}=1 \cdot 25,95 \%$ CI $1 \cdot 02,1 \cdot 53)$, drinking alcohol less than once a week $(O R=1 \cdot 37,95 \%$ CI $1 \cdot 12,1 \cdot 67)$ and being of high socio-economic status compared to low status (OR $=1 \cdot 45,95 \%$ CI $1 \cdot 06,2 \cdot 00)$.

Table 2 shows that, after adjustment, frequent intake of high-dose vitamin $\mathrm{C}$ remained significantly associated with a personal history of any cancer $(\mathrm{OR}=1 \cdot 33,95 \% \mathrm{CI}$
$1 \cdot 00,1 \cdot 76)$ and any hormone-related cancer $(\mathrm{OR}=1 \cdot 68$, $95 \%$ CI $1 \cdot 16,2 \cdot 43)$, specifically breast cancer (OR $=1 \cdot 70$, $95 \%$ CI $1 \cdot 14,2 \cdot 55)$. In addition, frequent high-dose intake was significantly greater for women with a family history of breast cancer $(\mathrm{OR}=1 \cdot 26,95 \%$ CI $1 \cdot 01,1 \cdot 58)$ and appeared more likely in women with a family history of any cancer $(\mathrm{OR}=1 \cdot 16,95 \% \mathrm{CI} 0 \cdot 95,1 \cdot 41)$, any hormonerelated cancer $(\mathrm{OR}=1 \cdot 19$, 95\% CI 0.98, 1.46) and pancreatic cancer $(\mathrm{OR}=1 \cdot 44,95 \% \mathrm{CI} 0 \cdot 94,2 \cdot 21)$. The intake of any dose of vitamin $\mathrm{C}$ was significantly associated with a family history of cancer of the uterus $(\mathrm{OR}=1 \cdot 38,95 \%$ CI $1 \cdot 10,1 \cdot 74)$. These results were very similar when the analysis was weighted to take into account differential sampling in each season. For instance, the seasonally weighted odds of being a high-dose user with a personal history of breast cancer was $1 \cdot 61$ (95\% CI $1 \cdot 07,2 \cdot 41)$, or was $1.29(95 \%$ CI $1.03,1.62)$ with a family history of breast cancer or $1.53(95 \%$ CI $0.99,2.36)$ with a family history of pancreatic cancer. However, the result for a personal history of total cancers was not significant $(\mathrm{OR}=1 \cdot 30,95 \% \mathrm{CI} 0 \cdot 97,1 \cdot 73)$ after seasonal weighting.

It may be observed in Table 3 that the odds of vitamin $C$ use increased with increasing dose $>500 \mathrm{mg}$ for women who had any family member with a history of breast cancer or who had a personal history of breast cancer. For the latter, OR were $1.09(95 \%$ CI $0 \cdot 78,1.52)$ at $\geq 500 \mathrm{mg}$, $1 \cdot 70(95 \%$ CI $1 \cdot 14,2 \cdot 55)$ at $\geq 1000 \mathrm{mg}$ and $2 \cdot 36(95 \% \mathrm{CI}$ $1 \cdot 00,5 \cdot 56)$ at $\geq 2000 \mathrm{mg}$. A similar pattern occurs for those with a personal history of cancer of the uterus or cervix, and was also seen in the total analyses of any cancer or any hormone-related cancer. The small numbers of women in some of the categories, however, may have produced spurious results. Although the odds of having a mother or sister with breast cancer or potentially being at raised risk of this cancer increased at higher intakes, these were not statistically significant.

It may be observed in Table 4 that high-dose takers also had greater odds of having a personal history of cardiovascular and intestinal disorders after adjustment $(\mathrm{OR}=$ $1 \cdot 27,95 \%$ CI 1·02, 1·59; and OR $=1 \cdot 25,95 \%$ CI 1·03, 1·51, respectively). Specifically, they had double the odds of a history of angina (OR $=2 \cdot 05,95 \%$ CI $1 \cdot 21,3 \cdot 45)$ and an increased risk of reporting haemorrhoids ( OR $=1 \cdot 26,95 \%$ CI $1 \cdot 01,1 \cdot 56$ ), irritable bowel syndrome (IBS; OR $=1 \cdot 27$, $95 \%$ CI $0.98,1.64)$ and anal fissures (OR $=1.41,95 \%$ CI $0 \cdot 95,2 \cdot 09)$. Generally, vitamin C supplementation was not significantly associated with a family history of morbidities in Table 4; however, a high intake was significantly associated with a family history of high blood pressure $(\mathrm{OR}=1 \cdot 30,95 \% \mathrm{CI} 1 \cdot 07,1 \cdot 57)$, and any vitamin $\mathrm{C}$ intake was significantly associated with a family history of high cholesterol $(\mathrm{OR}=1 \cdot 16,95 \% \mathrm{CI} 1 \cdot 01,1 \cdot 33)$. The use of supplements containing any dose of vitamin C was significantly associated with both a family and personal history of arthritis. Conversely, women with diabetes mellitus were less likely to take them. 
Table 1 Characteristics associated with the intake of supplements containing any dose of vitamin $\mathrm{C}$ and the intake of supplements containing high doses of vitamin $\mathrm{C}(\geq 1000 \mathrm{mg})$

\begin{tabular}{|c|c|c|c|c|c|c|}
\hline \multirow[b]{2}{*}{ Characteristics } & \multicolumn{2}{|c|}{ Any dose } & \multirow[b]{2}{*}{$P$ value } & \multicolumn{2}{|c|}{$\geq 1000 \mathrm{mg}$} & \multirow[b]{2}{*}{$P$ value } \\
\hline & $\mathrm{OR}^{*}$ & $95 \% \mathrm{Cl}$ & & $\mathrm{OR}^{*}$ & $95 \% \mathrm{Cl}$ & \\
\hline \multicolumn{7}{|l|}{ Age (years) $\dagger$} \\
\hline$<45$ & $1 \cdot 00$ & Ref. & \multirow[t]{4}{*}{0.07} & $1 \cdot 00$ & Ref. & \multirow{4}{*}{$0 \cdot 3$} \\
\hline $45-54$ & $1 \cdot 20$ & $1 \cdot 03,1 \cdot 41$ & & $1 \cdot 11$ & $0 \cdot 81,1 \cdot 54$ & \\
\hline $55-64$ & $1 \cdot 26$ & $1 \cdot 07,1 \cdot 48$ & & 0.85 & $0 \cdot 60,1 \cdot 20$ & \\
\hline$\geq 65$ & $1 \cdot 23$ & $1 \cdot 03,1 \cdot 47$ & & 0.91 & $0 \cdot 62,1 \cdot 34$ & \\
\hline \multicolumn{7}{|l|}{ Social class $\ddagger$} \\
\hline High & $1 \cdot 00$ & Ref. & \multirow[t]{3}{*}{$0 \cdot 1$} & $1 \cdot 00$ & Ref. & \multirow[t]{3}{*}{0.04} \\
\hline Intermediate & $1 \cdot 10$ & $1 \cdot 01,1 \cdot 21$ & & 0.96 & $0 \cdot 78,1 \cdot 17$ & \\
\hline Low & $1 \cdot 07$ & $0 \cdot 94,1 \cdot 22$ & & 0.69 & $0.50,0.94$ & \\
\hline \multicolumn{7}{|l|}{ Marital status $\ddagger$} \\
\hline Married or living together & $1 \cdot 00$ & Ref. & \multirow[t]{4}{*}{$0 \cdot 4$} & $1 \cdot 00$ & Ref. & \multirow[t]{4}{*}{$0 \cdot 9$} \\
\hline Divorced/separated & $1 \cdot 31$ & $1 \cdot 14,1 \cdot 51$ & & $1 \cdot 25$ & $0.94,1.66$ & \\
\hline Widowed & 0.95 & $0 \cdot 78,1 \cdot 16$ & & $1 \cdot 14$ & $0 \cdot 72,1 \cdot 80$ & \\
\hline Single & 0.86 & $0.72,1.03$ & & 0.88 & $0 \cdot 61,1 \cdot 28$ & \\
\hline \multicolumn{7}{|l|}{ Had children } \\
\hline Yes & $1 \cdot 00$ & Ref. & \multirow[t]{2}{*}{0.001} & $1 \cdot 00$ & Ref. & \multirow[t]{2}{*}{0.09} \\
\hline \multirow{2}{*}{\multicolumn{7}{|c|}{ BMI $\left(\mathrm{kg} / \mathrm{m}^{2}\right) \dagger$}} \\
\hline & & & & & & \\
\hline Underweight (<18.00) & 1.03 & $0 \cdot 72,1 \cdot 46$ & \multirow{4}{*}{$0 \cdot 08$} & $1 \cdot 07$ & $0 \cdot 53,2 \cdot 15$ & \\
\hline Normal (18.00-24.99) & $1 \cdot 00$ & Ref. & & $1 \cdot 00$ & Ref. & 0.6 \\
\hline Overweight (25·00-29.99) & 0.90 & $0.82,0.99$ & & 0.87 & $0.69,1.09$ & \\
\hline Obese $(\geq 30 \cdot 00)$ & 0.93 & $0 \cdot 80,1 \cdot 07$ & & $1 \cdot 11$ & $0 \cdot 81,1 \cdot 54$ & \\
\hline Smoking statusł & & & & & & \\
\hline Never smoked & $1 \cdot 00$ & Ref. & $0 \cdot 4$ & $1 \cdot 00$ & Ref. & 0.02 \\
\hline Ex-smoker & $1 \cdot 07$ & $0 \cdot 98,1 \cdot 17$ & & $1 \cdot 25$ & $1 \cdot 02,1 \cdot 53$ & \\
\hline Current smoker & 0.91 & $0 \cdot 75,1 \cdot 00$ & & $1 \cdot 19$ & $0 \cdot 79,1 \cdot 81$ & \\
\hline Drinks alcohol more than once a wee & & & & & & \\
\hline Yes & $1 \cdot 00$ & Ref. & $0 \cdot 1$ & $1 \cdot 00$ & Ref. & 0.001 \\
\hline No & $1 \cdot 07$ & $0 \cdot 98,1 \cdot 17$ & & $1 \cdot 37$ & $1 \cdot 12,1 \cdot 67$ & \\
\hline Physical activity & & & & & & \\
\hline No weekly physical activity & $1 \cdot 00$ & Ref. & $<0.001$ & $1 \cdot 00$ & Ref. & 0.008 \\
\hline Light moderate (most weeks) & $1 \cdot 16$ & $0 \cdot 95,1 \cdot 41$ & & 0.94 & $0 \cdot 60,1 \cdot 48$ & \\
\hline Vigorous (1-2 times/week) & $1 \cdot 18$ & $0.96,1 \cdot 46$ & & 0.98 & $0.61,1.57$ & \\
\hline Vigorous ( $\geq 3$ times/week) & $1 \cdot 52$ & $1 \cdot 23,1 \cdot 89$ & & $1 \cdot 36$ & $0 \cdot 85,2 \cdot 19$ & \\
\hline Servings of red meat eaten/week & & & & & & \\
\hline None & $1 \cdot 00$ & Ref. & $<0.001$ & $1 \cdot 00$ & Ref. & $<0.001$ \\
\hline $1-3$ & 0.79 & $0 \cdot 72,0 \cdot 87$ & & $0 \cdot 68$ & $0.55,0.85$ & \\
\hline$\geq 4$ & 0.61 & $0.54,0.68$ & & 0.48 & $0.35,0.65$ & \\
\hline Servings of fruit and vegetables eater & & & & & & \\
\hline$\leq 2$ & $1 \cdot 00$ & Ref. & $<0.001$ & $1 \cdot 00$ & Ref. & $0 \cdot 01$ \\
\hline $3-5$ & $1 \cdot 21$ & $1 \cdot 08,1 \cdot 37$ & & $1 \cdot 11$ & $0 \cdot 84,1 \cdot 48$ & \\
\hline$>5$ & $1 \cdot 45$ & $1 \cdot 26,1 \cdot 67$ & & $1 \cdot 40$ & $1 \cdot 02,1 \cdot 92$ & \\
\hline Number of visits to doctors in past 12 & & & & & & \\
\hline None & $1 \cdot 00$ & Ref. & $<0.001$ & $1 \cdot 00$ & Ref. & $0 \cdot 9$ \\
\hline $1-4$ & $1 \cdot 27$ & $1 \cdot 12,1 \cdot 42$ & & 0.98 & $0 \cdot 76,1 \cdot 25$ & \\
\hline$>4$ & $1 \cdot 45$ & $1 \cdot 26,1 \cdot 67$ & & 0.98 & $0 \cdot 72,1 \cdot 33$ & \\
\hline Number of visits to alternative practiti & & & & & & \\
\hline None & $1 \cdot 00$ & Ref. & $<0.001$ & $1 \cdot 00$ & Ref. & $<0.001$ \\
\hline $1-4$ & $1 \cdot 41$ & $1 \cdot 23,1 \cdot 61$ & & $1 \cdot 77$ & $1 \cdot 35,2 \cdot 31$ & \\
\hline$>4$ & $1 \cdot 75$ & $1 \cdot 51,2 \cdot 03$ & & $2 \cdot 84$ & $2 \cdot 20,3 \cdot 66$ & \\
\hline Number of participants in the models & & 10161 & & & 10161 & \\
\hline
\end{tabular}

Ref., reference category.

${ }^{*}$ Mutually adjusted for the other variables listed above.

$+P$ for trend over the continuous variables.

$\ddagger P$ for trend over categories.

\section{Discussion}

The frequent intake of supplements containing any dose or high doses of vitamin C in the UKWCS was associated with healthier lifestyle behaviours, and therefore supports the inverse supplement hypothesis, as seen in the analyses of any supplement intake in the UK or elsewhere $^{(4,7-14)}$. Women taking either high $(\geq 1000 \mathrm{mg} / \mathrm{d})$ or any dose of vitamin $\mathrm{C}$ were more likely to consume over five servings of fruit and vegetables, the main dietary source of vitamin $\mathrm{C}^{(17)}$. This is consistent with evidence from the studies of any supplement intake $\mathrm{e}^{(6,7,12)}$ and US studies on the intake of vitamin C supplements ${ }^{(9,12)}$, and suggests that many high-dose vitamin $C$ takers are less likely to need them. Furthermore, in line with US findings, UKWCS vitamin C takers were likely to eat less meat ${ }^{(10)}$. 
Table 2 OR of taking supplements containing vitamin C: any dose or $\geq 1000 \mathrm{mg}$ for UKWCS women who self-reported a personal or a family history of cancer

\begin{tabular}{|c|c|c|c|c|c|c|c|c|c|}
\hline \multirow[b]{3}{*}{ Type of cancer } & \multirow[b]{3}{*}{$n+$} & \multicolumn{4}{|c|}{ Any dose ( $n$ 4242; $34 \%)$} & \multicolumn{4}{|c|}{$\geq 1000 \mathrm{mg}(n 579 ; 5 \%)$} \\
\hline & & \multicolumn{2}{|c|}{ Unadjusted } & \multicolumn{2}{|c|}{ Adjusted $^{*}$} & \multicolumn{2}{|c|}{ Unadjusted } & \multicolumn{2}{|c|}{ Adjusted $^{*}$} \\
\hline & & OR & $95 \% \mathrm{Cl}$ & OR & $95 \% \mathrm{Cl}$ & OR & $95 \% \mathrm{Cl}$ & OR & $95 \% \mathrm{Cl}$ \\
\hline \multicolumn{10}{|l|}{ Personal history } \\
\hline Any cancer & 1268 & $1 \cdot 14$ & $1 \cdot 01,1 \cdot 29$ & $1 \cdot 12$ & $0.97,1 \cdot 28$ & $1 \cdot 31$ & $1 \cdot 02,1 \cdot 68$ & $1 \cdot 33$ & $1 \cdot 00,1 \cdot 76$ \\
\hline Any hormone & 642 & $1 \cdot 11$ & $0.94,1 \cdot 31$ & $1 \cdot 08$ & $0 \cdot 89,1 \cdot 31$ & $1 \cdot 50$ & $1 \cdot 09,2 \cdot 08$ & 1.68 & $1 \cdot 16,2 \cdot 43$ \\
\hline Breast & 523 & $1 \cdot 13$ & $0.94,1 \cdot 36$ & $1 \cdot 10$ & $0 \cdot 89,1 \cdot 35$ & 1.53 & $1 \cdot 08,2 \cdot 18$ & $1 \cdot 70$ & $1 \cdot 14,2 \cdot 55$ \\
\hline Uterus & 75 & 0.85 & $0.52,1 \cdot 39$ & 0.77 & $0 \cdot 44,1 \cdot 34$ & $1 \cdot 78$ & $0 \cdot 77,4 \cdot 12$ & 1.97 & $0.77,5.02$ \\
\hline Ovarian & 60 & $1 \cdot 29$ & $0 \cdot 77,2 \cdot 17$ & $1 \cdot 28$ & $0 \cdot 71,2 \cdot 33$ & $1 \cdot 35$ & $0.60,3.07$ & $0 \cdot 84$ & $0.20,3.51$ \\
\hline Any non-hormone cancer & 584 & $1 \cdot 16$ & $0.98,1.40$ & $1 \cdot 11$ & $0.91,1 \cdot 34$ & $1 \cdot 16$ & $0 \cdot 80,1 \cdot 70$ & $1 \cdot 05$ & $0.68,1.60$ \\
\hline Skin & 324 & $1 \cdot 14$ & $0.91,1.43$ & 1.04 & $0 \cdot 81,1 \cdot 34$ & 0.85 & $0.48,1 \cdot 49$ & $0 \cdot 71$ & $0.36,1 \cdot 39$ \\
\hline Cervix & 190 & $1 \cdot 26$ & $0.94,1.69$ & $1 \cdot 20$ & $0.86,1.66$ & $2 \cdot 03$ & $1 \cdot 22,3 \cdot 36$ & $1 \cdot 70$ & $0.94,3.05$ \\
\hline Colon/rectum & 63 & $1 \cdot 19$ & $0 \cdot 71,1 \cdot 98$ & $1 \cdot 30$ & $0 \cdot 73,2 \cdot 30$ & $1 \cdot 07$ & $0 \cdot 34,3 \cdot 44$ & 0.98 & $0 \cdot 24,4 \cdot 10$ \\
\hline \multicolumn{10}{|l|}{ Family history } \\
\hline Any cancer & 7259 & $1 \cdot 08$ & $1 \cdot 00,1 \cdot 16$ & 1.04 & $0.96,1 \cdot 13$ & $1 \cdot 15$ & $0.97,1.36$ & $1 \cdot 16$ & $0.95,1.41$ \\
\hline Any hormone cancer & 3629 & $1 \cdot 09$ & $1 \cdot 01,1 \cdot 18$ & 1.09 & $0.99,1 \cdot 19$ & $1 \cdot 16$ & $0.97,1.38$ & $1 \cdot 19$ & $0.98,1.46$ \\
\hline Breast & 2370 & $1 \cdot 06$ & $0 \cdot 97,1 \cdot 17$ & 1.04 & $0 \cdot 94,1 \cdot 16$ & $1 \cdot 23$ & $1 \cdot 00,1 \cdot 51$ & $1 \cdot 26$ & $1.01,1.58$ \\
\hline Prostate & 958 & $1 \cdot 09$ & $0.95,1.25$ & $1 \cdot 13$ & $0.97,1.32$ & 1.04 & $0 \cdot 76,1 \cdot 41$ & $1 \cdot 09$ & $0.77,1.51$ \\
\hline Ovarian & 423 & $1 \cdot 10$ & $0.90,1 \cdot 35$ & $1 \cdot 12$ & $0.90,1.41$ & 1.07 & $0 \cdot 69,1 \cdot 70$ & 1.09 & $0.66,1.79$ \\
\hline Uterus & 380 & $1 \cdot 41$ & $1 \cdot 14,1 \cdot 73$ & $1 \cdot 38$ & $1 \cdot 10,1 \cdot 74$ & $1 \cdot 08$ & $0.68,1 \cdot 73$ & $1 \cdot 11$ & $0 \cdot 66,1 \cdot 87$ \\
\hline Any non-hormone cancer & 5227 & $1 \cdot 07$ & $0 \cdot 99,1 \cdot 16$ & 1.03 & $0 \cdot 95,1 \cdot 12$ & $1 \cdot 03$ & $0 \cdot 87,1 \cdot 22$ & $1 \cdot 04$ & $0 \cdot 86,1 \cdot 25$ \\
\hline Lung & 2066 & 1.06 & $0 \cdot 96,1 \cdot 17$ & $1 \cdot 00$ & $0 \cdot 89,1 \cdot 11$ & $1 \cdot 07$ & $0.86,1 \cdot 33$ & $1 \cdot 00$ & $0.78,1 \cdot 29$ \\
\hline Colon/rectum & 1608 & 0.96 & $0 \cdot 86,1 \cdot 08$ & 0.98 & $0 \cdot 86,1 \cdot 11$ & 0.97 & $0 \cdot 76,1 \cdot 25$ & $1 \cdot 08$ & $0 \cdot 82,1 \cdot 43$ \\
\hline Stomach & 1300 & $1 \cdot 02$ & $0 \cdot 90,1 \cdot 15$ & 1.01 & $0 \cdot 88,1 \cdot 16$ & 0.91 & $0 \cdot 69,1 \cdot 21$ & 0.97 & $0.71,1 \cdot 33$ \\
\hline Skin & 957 & $1 \cdot 01$ & $0 \cdot 88,1 \cdot 16$ & 0.97 & $0 \cdot 83,1 \cdot 13$ & $0 \cdot 88$ & $0.64,1 \cdot 23$ & $0 \cdot 86$ & $0 \cdot 60,1 \cdot 24$ \\
\hline Pancreas & 455 & $1 \cdot 13$ & $0.93,1.37$ & $1 \cdot 11$ & $0 \cdot 90,1 \cdot 38$ & $1 \cdot 41$ & $0.96,2 \cdot 08$ & $1 \cdot 44$ & $0 \cdot 94,2 \cdot 21$ \\
\hline Cervix & 311 & $1 \cdot 03$ & $0 \cdot 81,1 \cdot 31$ & 1.04 & $0 \cdot 79,1 \cdot 36$ & 0.68 & $0 \cdot 36,1 \cdot 28$ & 0.74 & $0.38,1 \cdot 46$ \\
\hline
\end{tabular}

${ }^{*}$ Adjusted for BMI, age, social class, marital status, children, smoking status, level of physical activity, low alcohol consumption, red meat servings, total fruit and vegetable servings.

tTotal numbers with history of cancer.

They also exercised vigorously more often, supporting previous research linking activity to supplement intake $^{(6-8,11-14)}$. Distinguishing characteristics of highdose vitamin $\mathrm{C}$ takers in the UKWCS were being an ex-smoker, drinking alcohol less than once a week and being of high socio-economic status. These characteristics were not significant predictors of using supplements containing any dose of vitamin C in the UKWCS; however, they have been positively associated with taking any type of supplement in other studies ${ }^{(5,8)}$. In addition, highdose vitamin $\mathrm{C}$ takers appeared to rely more on alternative practitioners rather than family or private doctors. Healthy behaviours associated with the intake of vitamin C supplements are likely to reduce health risks; therefore, these behaviours identified should be considered for adjustment in longitudinal studies of risks ${ }^{(12)}$.

Despite controversy surrounding evidence of benefits of high-dose vitamin C supplementation for prolonged cancer survival $^{(32-34)}$, our results showed prior to seasonal weighting that women with any type of cancer were more likely to be high-dose vitamin C supplement takers than women with no history of cancer. Since antioxidants can potentially reduce the effectiveness of anti-cancer drugs ${ }^{(35,36)}$, patients should be encouraged to discuss their supplement use with their doctors in order to avoid contraindications. For some cancer patients, supplement use may be a coping behaviour and a way of taking control $^{(37,38)}$. Similar health-related behaviours may also occur in women with concerns about risk of developing cancer: for instance, women who attended mammography have also been positively associated with the intake of supplements in the USA ${ }^{(12)}$. Similarly, women attending UK breast screening clinics had similar characteristics to supplement takers in the UKWCS and wanted diet and exercise advice to be provided at these clinics ${ }^{(39)}$. Lower doses and any dose of vitamin C, however, were not significantly associated with total cancer in the UKWCS; this has also been observed in some US studies ${ }^{(22,40)}$.

To the best of our knowledge, this is the first UK study to analyse associations between the use of vitamin $\mathrm{C}$ supplements and specific prevalent cancers, and therefore the first to report significant associations of frequent intake of high-dose vitamin $C(\geq 1000 \mathrm{mg} / \mathrm{d})$ in UK women with a personal or family history of breast cancer. This supports findings that US women physicians with breast cancer were more likely to take vitamin $\mathrm{C}^{(10)}$. Furthermore, our results show that the odds of having a history of cancer increased at higher doses ( $\geq 2000 \mathrm{mg}$ ). However, while US research found that women at a high risk of breast cancer and with inconclusive genetic test results were significantly more likely to take any supplements, the increased odds of high-dose vitamin $\mathrm{C}$ 
Table 3 OR of taking supplements containing vitamin C for a range of doses for the UK Women's Cohort Study women who self-reported a personal history of cancer or a family history of breast cancer

\begin{tabular}{|c|c|c|c|c|c|c|c|c|c|c|c|c|}
\hline & \multirow[b]{3}{*}{$n+$} & \multicolumn{11}{|c|}{ Frequent intake of vitamin $C$ doses } \\
\hline & & \multicolumn{2}{|c|}{$\geq 250 \mathrm{mg} \mathrm{(n} \mathrm{1448;12 \% )}$} & \multirow[b]{2}{*}{$n+$} & \multicolumn{2}{|c|}{$\geq 500 \mathrm{mg}(n 1195 ; 10 \%)$} & \multirow[b]{2}{*}{$n+$} & \multicolumn{2}{|c|}{$\geq 1000 \mathrm{mg}(n 579 ; 5 \%)$} & \multirow[b]{2}{*}{$n+$} & \multicolumn{2}{|c|}{$\geq 2000 \mathrm{mg}(n 92 ; 1 \%)$} \\
\hline & & $\mathrm{OR}^{*}$ & $95 \% \mathrm{Cl}$ & & $\mathrm{OR}^{*}$ & $95 \% \mathrm{Cl}$ & & $\mathrm{OR}^{*}$ & $95 \% \mathrm{Cl}$ & & $\mathrm{OR}^{\star}$ & $95 \% \mathrm{Cl}$ \\
\hline \multicolumn{13}{|l|}{ Personal history } \\
\hline Any cancer & 159 & 1.06 & $0.87,1 \cdot 30$ & 131 & 1.03 & $0.83,1.29$ & 74 & $1 \cdot 33$ & $1 \cdot 00,1 \cdot 76$ & 19 & $2 \cdot 86$ & $1 \cdot 64,4.98$ \\
\hline Any hormone cancer & 81 & 1.04 & $0.79,1.39$ & 69 & $1 \cdot 08$ & $0.80,1.46$ & 43 & $1 \cdot 68$ & $1 \cdot 16,2 \cdot 43$ & 12 & $3 \cdot 50$ & $1 \cdot 75,7 \cdot 01$ \\
\hline Breast cancer & 68 & $1 \cdot 10$ & $0 \cdot 81,1 \cdot 49$ & 56 & 1.09 & $0.78,1.52$ & 36 & $1 \cdot 70$ & $1 \cdot 14,2 \cdot 55$ & 8 & $2 \cdot 36$ & $1 \cdot 00,5 \cdot 56$ \\
\hline Uterus & 8 & 0.99 & $0.45,2 \cdot 22$ & 8 & $1 \cdot 25$ & $0.56,2 \cdot 78$ & 6 & $1 \cdot 97$ & $0.77,5.02$ & 3 & $8 \cdot 64$ & $2 \cdot 52,29 \cdot 6$ \\
\hline Ovarian & 7 & 0.50 & $0 \cdot 15,1 \cdot 62$ & 7 & 0.64 & $0.20,2.06$ & 3 & 0.84 & $0.20,3.51$ & 1 & $2 \cdot 75$ & $0 \cdot 37,20 \cdot 8$ \\
\hline Any non-hormone cancer & 69 & 0.98 & $0 \cdot 73,1 \cdot 30$ & 56 & 0.97 & $0 \cdot 71,1 \cdot 33$ & 31 & 1.05 & $0 \cdot 68,1 \cdot 60$ & 8 & $2 \cdot 52$ & $1 \cdot 19,5 \cdot 32$ \\
\hline Skin & 34 & 0.79 & $0.53,1.20$ & 26 & 0.74 & $0 \cdot 47,1 \cdot 19$ & 13 & $0 \cdot 71$ & $0.36,1.39$ & 2 & $1 \cdot 08$ & $0 \cdot 26,4 \cdot 49$ \\
\hline Cervix & 32 & $1 \cdot 43$ & $0 \cdot 93,2 \cdot 21$ & 29 & 1.60 & $1 \cdot 03,2.52$ & 17 & $1 \cdot 70$ & $0.94,3.05$ & 4 & $3 \cdot 14$ & $1 \cdot 10,8 \cdot 94$ \\
\hline Colon/rectum & 5 & 0.69 & $0 \cdot 24,1 \cdot 94$ & 3 & 0.41 & $0 \cdot 10,1 \cdot 72$ & 3 & 0.98 & $0 \cdot 24,4 \cdot 10$ & 2 & $7 \cdot 20$ & $1 \cdot 62,32 \cdot 1$ \\
\hline \multicolumn{13}{|l|}{ Family history of breast cancer } \\
\hline Any family member & 299 & $1 \cdot 15$ & $0.99,1.34$ & 244 & $1 \cdot 10$ & $0.93,1 \cdot 30$ & 129 & $1 \cdot 26$ & $1 \cdot 01,1 \cdot 58$ & 27 & $1 \cdot 69$ & $1 \cdot 01,2 \cdot 83$ \\
\hline Mother or sister & 163 & $1 \cdot 13$ & $0.93,1.37$ & 129 & 1.04 & $0.84,1 \cdot 29$ & 67 & $1 \cdot 16$ & $0.87,1.55$ & 15 & 1.55 & $0.81,2 \cdot 96$ \\
\hline Respondent at raised risk & 32 & $1 \cdot 11$ & $0.73,1.68$ & 25 & 1.04 & $0.66,1.65$ & 15 & $1 \cdot 31$ & $0.73,2.32$ & 4 & 2.03 & $0.62,6.56$ \\
\hline Respondent at high risk‡ & 9 & 0.67 & $0.30,1.47$ & 8 & 0.71 & $0.31,1.65$ & 4 & 0.69 & $0 \cdot 22,2 \cdot 23$ & & & \\
\hline
\end{tabular}

${ }^{*}$ Adjusted for BMI, age, social class, marital status, children, smoking status, level of physical activity, low alcohol consumption, red meat servings, total fruit and vegetable servings. Comparison group = all respondents not taking stated dose.

tTotal numbers with a history of cancer listed taking doses specified.

łlnsufficient numbers at higher doses. 
Table 4 OR of taking supplements containing vitamin C: any dose or $\geq 1000 \mathrm{mg}$ for the UK Women's Cohort Study women who selfreported a family history or personal history of other illnesses

\begin{tabular}{|c|c|c|c|c|c|c|c|c|c|}
\hline \multirow[b]{3}{*}{ Type of illness } & \multirow[b]{3}{*}{$n$} & \multicolumn{4}{|c|}{ Any dose } & \multicolumn{4}{|c|}{$\geq 1000 \mathrm{mg}$ (yes/no) } \\
\hline & & \multicolumn{2}{|c|}{ Unadjusted } & \multicolumn{2}{|c|}{ Adjusted* } & \multicolumn{2}{|c|}{ Unadjusted } & \multicolumn{2}{|c|}{ Adjusted* } \\
\hline & & OR & $95 \% \mathrm{Cl}$ & OR & $95 \% \mathrm{Cl}$ & OR & $95 \% \mathrm{Cl}$ & OR & $95 \% \mathrm{Cl}$ \\
\hline \multicolumn{10}{|l|}{ Personal history } \\
\hline CV-related disorders & 3217 & 0.90 & $0.83,0.98$ & 0.98 & $0.89,1.09$ & 1.00 & $0.83,1 \cdot 21$ & $1 \cdot 27$ & $1 \cdot 02,1.59$ \\
\hline Heart attack & 176 & $0 \cdot 83$ & $0 \cdot 60,1 \cdot 15$ & 0.90 & $0 \cdot 62,1 \cdot 30$ & $1 \cdot 22$ & $0 \cdot 64,2 \cdot 33$ & $1 \cdot 63$ & $0.81,3 \cdot 30$ \\
\hline Angina & 293 & 0.90 & $0 \cdot 70,1 \cdot 15$ & $1 \cdot 07$ & $0 \cdot 81,1 \cdot 41$ & $1 \cdot 42$ & $0 \cdot 88,2 \cdot 29$ & $2 \cdot 05$ & $1 \cdot 21,3 \cdot 45$ \\
\hline Stroke & 172 & $1 \cdot 15$ & $0.84,1.57$ & $1 \cdot 13$ & $0.79,1.60$ & $1 \cdot 13$ & $0.58,2 \cdot 23$ & $1 \cdot 50$ & $0 \cdot 72,3 \cdot 11$ \\
\hline High blood pressure & 2302 & $0 \cdot 88$ & $0.80,0.97$ & 0.97 & $0.87,1.09$ & 0.96 & $0 \cdot 77,1 \cdot 19$ & $1 \cdot 20$ & $0.93,1.54$ \\
\hline High cholesterol & 1246 & 0.99 & $0 \cdot 88,1 \cdot 12$ & $1 \cdot 07$ & $0.92,1.23$ & 0.98 & $0 \cdot 74,1 \cdot 29$ & $1 \cdot 19$ & $0.86,1.64$ \\
\hline Diabetes & 265 & 0.64 & $0.48,0.84$ & $0 \cdot 71$ & $0.51,0.98$ & 0.47 & $0.21,1.06$ & 0.62 & $0.25,1.53$ \\
\hline Gallstones & 748 & 0.97 & $0 \cdot 83,1 \cdot 13$ & $1 \cdot 00$ & $0 \cdot 83,1 \cdot 19$ & 0.96 & $0.68,1.37$ & $1 \cdot 04$ & $0.69,1.57$ \\
\hline Intestine disorders & 4716 & $1 \cdot 21$ & $1 \cdot 12,1 \cdot 30$ & $1 \cdot 23$ & $1 \cdot 13,1 \cdot 34$ & $1 \cdot 22$ & $1 \cdot 03,1.45$ & $1 \cdot 25$ & $1.03,1.51$ \\
\hline Polyps & 179 & $0 \cdot 88$ & $0 \cdot 64,1 \cdot 21$ & 0.93 & $0 \cdot 65,1 \cdot 33$ & $0 \cdot 83$ & $0 \cdot 39,1 \cdot 80$ & $1 \cdot 02$ & $0 \cdot 44,2 \cdot 34$ \\
\hline Stomach ulcer & 941 & $1 \cdot 17$ & $1 \cdot 02,1 \cdot 34$ & $1 \cdot 20$ & $1 \cdot 02,1 \cdot 39$ & 1.02 & $0 \cdot 75,1 \cdot 39$ & $1 \cdot 14$ & $0.82,1.61$ \\
\hline IBS & 1650 & $1 \cdot 30$ & $1 \cdot 17,1 \cdot 44$ & $1 \cdot 31$ & $1 \cdot 16,1 \cdot 47$ & $1 \cdot 27$ & $1 \cdot 01,1 \cdot 60$ & $1 \cdot 27$ & $0.98,1.64$ \\
\hline Haemorrhoids & 2716 & $1 \cdot 08$ & $0.99,1 \cdot 18$ & $1 \cdot 07$ & $0.97,1 \cdot 19$ & $1 \cdot 23$ & $1 \cdot 01,1 \cdot 49$ & $1 \cdot 26$ & $1 \cdot 01,1.56$ \\
\hline Ulcerative colitis & 140 & 0.98 & $0.69,1.40$ & $1 \cdot 05$ & $0.69,1.58$ & $1 \cdot 07$ & $0 \cdot 50,2 \cdot 30$ & $1 \cdot 07$ & $0.43,2.65$ \\
\hline Diverticular & 453 & $0 \cdot 88$ & $0.72,1.08$ & 0.97 & $0.77,1 \cdot 22$ & 0.69 & $0 \cdot 41,1 \cdot 16$ & 0.65 & $0.33,1 \cdot 28$ \\
\hline Anal fissure & 561 & $1 \cdot 20$ & $1.01,1.43$ & $1 \cdot 17$ & $0.96,1.43$ & $1 \cdot 29$ & $0.89,1.85$ & $1 \cdot 41$ & $0.95,2.09$ \\
\hline Arthritis & 3391 & $1 \cdot 20$ & $1 \cdot 10,1 \cdot 30$ & $1 \cdot 32$ & $1 \cdot 19,1 \cdot 45$ & 0.97 & $0 \cdot 80,1 \cdot 17$ & $1 \cdot 17$ & $0.93,1.47$ \\
\hline \multicolumn{10}{|l|}{ Family history } \\
\hline CV-related disorders & 9765 & $1 \cdot 03$ & $0.94,1.12$ & $1 \cdot 01$ & $0.91,1.12$ & $1 \cdot 20$ & $0.97,1.48$ & $1 \cdot 24$ & $0.96,1.59$ \\
\hline Heart attack & 5558 & 1.05 & $0.97,1.13$ & 1.06 & $0.97,1.15$ & $1 \cdot 12$ & $0.95,1.32$ & $1 \cdot 11$ & $0.92,1.34$ \\
\hline Angina & 2982 & 0.97 & $0.89,1.06$ & 0.95 & $0.86,1.05$ & $1 \cdot 20$ & $0.99,1.45$ & $1 \cdot 12$ & $0.91,1.38$ \\
\hline Stroke & 3799 & $1 \cdot 04$ & $0.96,1 \cdot 13$ & $1 \cdot 00$ & $0.91,1.09$ & 0.93 & $0 \cdot 77,1 \cdot 12$ & $0 \cdot 88$ & $0.72,1.09$ \\
\hline High blood pressure & 4358 & $1 \cdot 05$ & $0.97,1 \cdot 13$ & $1 \cdot 03$ & $0.94,1 \cdot 12$ & $1 \cdot 29$ & $1.09,1.53$ & $1 \cdot 30$ & $1 \cdot 07,1.57$ \\
\hline High cholesterol & 1185 & $1 \cdot 13$ & $0.99,1.28$ & $1 \cdot 16$ & $1 \cdot 01,1 \cdot 33$ & $1 \cdot 21$ & $0.93,1.58$ & $1 \cdot 21$ & $0.90,1.61$ \\
\hline Diabetes & 2320 & $1 \cdot 01$ & $0.92,1.11$ & 1.03 & $0.92,1.14$ & $1 \cdot 07$ & $0.87,1.33$ & $1 \cdot 13$ & $0.90,1.43$ \\
\hline Intestine disorders & 3102 & $1 \cdot 07$ & $0 \cdot 98,1 \cdot 17$ & $1 \cdot 07$ & $0 \cdot 97,1 \cdot 18$ & 0.99 & $0 \cdot 81,1 \cdot 20$ & $1 \cdot 00$ & $0 \cdot 81,1 \cdot 24$ \\
\hline Polyps & 295 & $1 \cdot 12$ & $0 \cdot 88,1 \cdot 42$ & 1.09 & $0.83,1.42$ & 0.64 & $0 \cdot 33,1 \cdot 25$ & $0 \cdot 50$ & $0 \cdot 22,1 \cdot 14$ \\
\hline Stomach ulcer & 1821 & $1 \cdot 05$ & $0.94,1 \cdot 16$ & $1 \cdot 03$ & $0.92,1 \cdot 16$ & 0.90 & $0 \cdot 71,1 \cdot 15$ & 0.90 & $0 \cdot 69,1 \cdot 19$ \\
\hline IBS & 1007 & $1 \cdot 06$ & $0.93,1.22$ & $1 \cdot 10$ & $0.94,1.28$ & $1 \cdot 23$ & $0.93,1.63$ & $1 \cdot 34$ & $0.99,1 \cdot 82$ \\
\hline Ulcerative colitis & 324 & 0.99 & $0 \cdot 79,1 \cdot 26$ & 0.99 & $0 \cdot 76,1 \cdot 28$ & $1 \cdot 07$ & $0.64,1.78$ & $1 \cdot 27$ & $0 \cdot 75,2 \cdot 18$ \\
\hline Anal fissure & 221 & $1 \cdot 31$ & $1 \cdot 00,1 \cdot 72$ & $1 \cdot 30$ & $0.96,1.75$ & 0.67 & $0.31,1 \cdot 42$ & 0.53 & $0.21,1 \cdot 29$ \\
\hline Arthritis & 5165 & $1 \cdot 20$ & $1 \cdot 12,1 \cdot 30$ & $1 \cdot 19$ & $1 \cdot 10,1 \cdot 30$ & $1 \cdot 12$ & $0.95,1.33$ & 1.09 & $0.90,1.31$ \\
\hline
\end{tabular}

CV, cardiovascular; IBS, irritable bowel syndrome.

*Adjusted for BMI, age, social class, marital status, no children, smoking status, level of physical activity, low alcohol consumption, red meat servings, total fruit and vegetable servings.

intake in the UKWCS for women with increased risk of hereditary breast cancer or those having mothers or sisters with breast cancer were not significant ${ }^{(41)}$. Our results may be due to low numbers and lack of power. In general, a history of non-hormone-related cancer did not appear to be associated with the intake of vitamin C supplements in the UKWCS. Nevertheless, associations with a personal history of cervical cancer remained significant at some doses after adjustments, including adjustment of socio-economic status, which is known to be linked with this cancer ${ }^{(42)}$.

In relation to the prevention of cancer, CVD and other chronic diseases, the 5-A-Day fruit and vegetable initiative based on the WHO recommendations could have influenced antioxidant supplement sales at the time of the UKWCS follow-up ${ }^{(43)}$. Proactive marketing by supplement companies would have also increased sales. The 1997 WCRF report, nevertheless, stated that supplements were probably unnecessary and unhelpful in reducing the risk of cancer ${ }^{(44)}$. While the recent 2007 WCRF report found no probable or convincing evidence that vitamin C supplementation affects the risk of cancer, there was evidence of an increased or decreased risk with some other supplement types, although this was usually from studies of high-risk groups ${ }^{(1)}$. In summary, the 2007 report states that it is unwise to recommend widespread supplement use for the prevention of cancer since the effects cannot be confidently predicted in the general population ${ }^{(1)}$. Indeed, high doses of some supplements, including vitamin C, may promote cancer ${ }^{(35)}$, although doses $>400 \mathrm{mg}$ of this water-soluble vitamin are likely to be excreted in healthy women $^{(45)}$. Its antioxidant properties may reduce DNA damage by reactive oxygen species (ROS) during the initial stage of cancer, particularly in individuals with high levels of $\operatorname{ROS}^{(35)}$. This antioxidant property, however, may decrease beneficial apoptosis, the ROS-induced programmed death of damaged cells ${ }^{(46)}$, and thereby lead to the progression of cancer, particularly in individuals with 
low levels of $\operatorname{ROS}^{(35)}$. Vitamin $\mathrm{C}$ may also act as a prooxidant creating highly reactive and damaging hydroxyl radicals via the Fenton reaction in the presence of iron ${ }^{(47)}$. However, this hypothesis is controversial since free iron is normally unavailable in vivo ${ }^{(47)}$. Apart from a family history of breast cancer and a moderate but non-significant association with a family history of pancreatic cancer, our results indicate that UK women were probably not taking high vitamin C supplements as a preventive measure due to a family history of cancer in general. Since cancer of the pancreas has a poor prognosis, women with this family history may have been more motivated to take high doses of vitamin $\mathrm{C}$ supplements.

In general, UKWCS respondents did not appear to take vitamin $\mathrm{C}$ for the prevention of other morbidities observed in their families. Only women with a family history of high blood pressure were significantly more likely to use a high dose of vitamin C, and those with a family history of high cholesterol or arthritis were significantly more likely to take any dose of vitamin C. In fact, a reduction in the risk of inflammatory polyarthritis (rheumatoid arthritis) has been linked to antioxidant intake ${ }^{(48)}$. Despite inconsistent evidence relating to associations between vitamin C supplementation and reduced CHD and hypertension ${ }^{(18-20,49)}$, women in the UKWCS, who had personally experienced cardiovascular-related diseases, specifically angina, were more likely to be high-dose users. Furthermore, US female physicians with hypertension were found to use vitamin C frequently ${ }^{(10)}$. However, this is not always the case since another US study found that risk factors for CVD were inversely associated with frequent intake of vitamin $\mathrm{C}$ $(\geq 150 \mathrm{mg} / \mathrm{d})^{(22)}$. Similarly, women with diabetes in our study were less likely to take any dose of vitamin C; it is unknown whether the burden of diabetic medication deters supplement taking or whether low levels of health literacy or health consciousness confound the negative association.

It is unknown why vitamin C supplements were used by women in the UKWCS. Given that only a relative small proportion of the UK population is advised by the medical profession to take a supplement for health reasons ${ }^{(5)}$, some health-conscious UK women with chronic conditions may be self-treating with vitamin C. Alternatively, those with disorders may use supplements under the belief that supplements can make them feel better generally or increase immune function ${ }^{(50)}$. In addition, due to the crosssectional nature of the study the direction of cause and effect cannot be determined; it is unknown whether vitamin $\mathrm{C}$ has been taken to prevent or manage symptoms of disorders or whether vitamin $\mathrm{C}$ has caused them. For instance, the associations observed with IBS could have been due to abdominal pain and diarrhoea caused by taking large doses of vitamin $\mathrm{C}^{(51)}$. However, the significant associations with IBS occurred at any dose of vitamin C, rather than at high dose specifically; therefore, a plausible explanation is that very health-conscious women who take supplements may be prone to anxiety, which might cause IBS ${ }^{(52)}$. This pattern of associations may reflect supplementing with multivitamins or antioxidant combinations containing vitamin C; the pattern was also seen with both a personal and family history of arthritis in the present study.

Lack of information to determine whether medical conditions developed before or after frequent intake of vitamin C supplements started is a limitation of the present study. Although data from the cancer registry were available for the cohort, we suggest that it is women's selfreported perceived health, whether accurate or not, that influences their supplement intake behaviour. Selfreporting of supplement descriptions for only $4 \mathrm{~d}$ by diary was a limitation of the study. While $4 \mathrm{~d}$ diaries are capable of capturing daily, and near daily intake, in reality some 3-4d diary recordings may represent spasmodic rather than frequent intake. Nevertheless, our results show that substantial agreement was found between these frequent diary recordings and daily use recorded concurrently by the questionnaire. Although the number of years of supplementation was not collected in either the diary or the questionnaire, and no further follow-up was conducted, the majority of vitamin C users (82\%) were taking a supplement of some type on average 4 years earlier at recruitment. An additional problem was the wide variety of formulations of supplements used, which made coding difficult. While high-dose vitamin C supplements were unlikely to contain other micronutrients ${ }^{(14)}$, our results show that, consistent with other research ${ }^{(5)}$, women taking high doses were highly likely to use other supplements. Therefore, vitamin C use may be a marker for the intake of other supplements.

Our study capitalises on the large sample size of the UKWCS, substantial numbers of women frequently taking vitamin C (34\%) and as well as the wide variety of characteristics and self-reported illnesses recorded. However, the small numbers of women in some of the categories, particularly those shown in Table 3, and especially those taking $\geq 2000 \mathrm{mg} / \mathrm{d}$, may have produced spurious results. Another limitation of the present study is that the UKWCS participants were more health conscious than the general population and therefore not representative of the whole UK population. Differences in characteristics between frequent users and non-frequent users in the UKWCS may not be as pronounced as that found in the general population.

Our research may help to identify high-dose users, such as ex-smokers, low alcohol drinkers and women with a history of breast cancer or other illnesses, who could be made aware of the inconsistencies in evidence relating to suggested benefits and about warnings relating to highstrength supplements ${ }^{(53)}$. Furthermore, patients should be encouraged to discuss their supplement use with their doctors to avoid contraindications ${ }^{(36,46)}$. Finally, additional research is needed to establish the effects of both supplement and dietary vitamin $\mathrm{C}$ intake on cancer initiation and development, as well as other illnesses. 


\section{Acknowledgements}

The creation of the UK Women's Cohort Study was funded by the World Cancer Research Fund. The authors declare that they have no conflicts of interest. J.D.T. managed the database. All other authors contributed to the design of the analysis and writing of the article. In addition, J.H. conducted the analysis and D.C.G. provided statistical advice.

\section{References}

1. World Cancer Research Fund \& American Institute for Cancer Research (2007) Food, Nutrition, Physical Activity, and the Prevention of Cancer: A Global Perspective. Washington, DC: American Institute for Cancer Research.

2. Bjelakovic G, Nikolova D, Gluud LL et al. (2007) Mortality in randomized trials of antioxidant supplements for primary and secondary prevention: systematic review and meta-analysis. JAMA 297, 842-857.

3. Hoare J, Henderson L, Bates C et al. (2004) The National Diet \& Nutrition Survey: Adults Aged 19 to 64 Years. Summary Report. London: HMSO.

4. Bates B, Lennox A \& Swan G (2009) The National Diet and Nutrition Survey: Headline results from Year 1 of the Rolling Programme (2008/2009). http://www.food.gov.uk/ multimedia/pdfs/publication/ndnsreport0809year1results. pdf (accessed January 2010).

5. GfK Social Research (2009) Consumer consumption of vitamin and mineral food supplements: Random Location Omnibus Survey 2008. http://www.food.gov.uk/multimedia/ pdfs/viminsupconsumer.pdf (accessed November 2009).

6. Kirk SFL, Cade JE, Barrett JH et al. (1999) Diet and lifestyle characteristics associated with dietary supplement use in women. Public Health Nutr 2, 69-73.

7. Harrison RA, Holt D, Pattison DJ et al. (2004) Are those in need taking dietary supplements? A survey of 21923 adults. Br J Nutr 91, 617-623.

8. McNaughton SA, Mishra GD, Paul AA et al. (2005) Supplement use is associated with health status and health-related behaviors in the 1946 British Birth Cohort. J Nutr 135, 1782-1789.

9. Brownie S (2005) Characteristics of older dietary supplement users: review of the literature. Aust J Ageing 24, 77-87.

10. Frank E, Bendich A \& Denniston M (2000) Use of vitaminmineral supplements by female physicians in the United States. Am J Clin Nutr 72, 969-975.

11. Lyle BJ, Mares-Perlman JA, Klein BEK et al. (1998) Supplement users differ from nonusers in demographic, lifestyle, dietary and health characteristics. J Nutr 128, 2355-2362.

12. Patterson RE, Neuhouser ML, White E et al. (1998) Cancerrelated behavior of vitamin supplement users. Cancer Epidemiol Biomarkers Prev 7, 79-81.

13. Reinert A, Rohrmann S, Becker N et al. (2007) Lifestyle and diet in people using dietary supplements. A German cohort study. Eur J Nutr 46, 165-173.

14. Shikany JM, Patterson RE, Agurs-Collins T et al. (2003) Antioxidant supplement use in Women's Health Initiative participants. Prev Med 36, 379-387.

15. Skeie G, Braaten T, Hjartaker A et al. (2009) Use of dietary supplements in the European Prospective Investigation into Cancer and Nutrition Calibration study. Eur J Clin Nutr 63, S226-SS38.

16. Hemilä H, Chalker E \& Douglas B (2007) Vitamin C for preventing and treating the common cold. Cochrane Database Syst Rev, issue 3, CD000980.
17. Khaw K-T, Bingham S, Welch A et al. (2001) Relation between plasma ascorbic acid and mortality in men and women in EPIC-Norfolk prospective study: a prospective population study. Lancet 357, 657-663.

18. Cook NR, Albert CM, Gaziano JM et al. (2007) A randomized factorial trial of vitamins $\mathrm{C}$ and $\mathrm{E}$ and $\beta$ carotene in the secondary prevention of cardiovascular events in women: results from the Women's Antioxidant Cardiovascular Study. Arch Intern Med 167, 1610-1618.

19. Kushi LH, Folsom AR, Prineas RJ et al. (1996) Dietary antioxidant vitamins and death from coronary heart disease in postmenopausal women. $N$ Engl J Med 334, 1156-1162.

20. Osganian SK, Stampfer MJ, Rimm E et al. (2003) Vitamin C and risk of coronary heart disease in women. $J$ Am Coll Cardiol 42, 246-252.

21. Velicer CM \& Ulrich CM (2008) Vitamin and mineral supplement use among US adults after cancer diagnosis: a systematic review. J Clin Oncol 26, 665-673.

22. Satia-Abouta J, Kristal AR, Patterson RE et al. (2003) Dietary supplement use and medical conditions: the VITAL study. Am J Prev Med 24, 43-51.

23. Cade JE, Burley VJ, Greenwood DC et al. (2004) The UK Women's Cohort Study: comparison of vegetarians, fisheaters and meat-eaters. Public Health Nutr 7, 871-878.

24. Cade JE, Burley VJ, Greenwood DC et al. (2007) Dietary fibre and risk of breast cancer in the UK Women's Cohort Study. Int J Epidemiol 36, 431-438.

25. Taylor EF, Burley VJ, Greenwood DC et al. (2007) Meat consumption and risk of breast cancer in the UK Women's Cohort Study. Br J Cancer 96, 1139-1146.

26. Expert Group on Vitamins and Minerals (2003) Risk assessment: vitamin C. http://cot.food.gov.uk/pdfs/vitmin2003.pdf (accessed August 2009).

27. The European Food Information Council (2009) Vitamins: what they do and where to find them. http://www.eufic.org/ article/en/page/MARCHIVE/expid/miniguide-vitamins/\#10 (accessed September 2009).

28. Riboli E \& Kaaks R (1997) The EPIC Project: rationale and study design. European Prospective Investigation into Cancer and Nutrition. Int J Epidemiol 26, Suppl. 1, S6-S14.

29. Spence M, Cade JE, Burley VJ et al. (2002) Ability of the UK Women's Cohort food frequency questionnaire to rank dietary intakes: a preliminary validation study. Proc Nutr Soc 61, 117A.

30. Hemilä H (1996) Vitamin C supplementation and common cold symptoms: problems with inaccurate reviews. Nutrition 12, 804-809.

31. National Institute for Health and Clinical Excellence (2006) Familial breast cancer. The classification and care of women at risk of familial breast cancer in primary, secondary and tertiary care. http://www.nice.org.uk/nicemedia/pdf/ CG41NICEguidance.pdf (accessed May 2009).

32. Cameron E \& Pauling L (1978) Supplemental ascorbate in the supportive treatment of cancer: reevaluation of prolongation of survival times in terminal human cancer. Proc Natl Acad Sci USA 75, 4538-4542.

33. Creagan ET, Moertel CG, O'Fallon JR et al. (1979) Failure of high-dose vitamin $\mathrm{C}$ (ascorbic acid) therapy to benefit patients with advanced cancer. A controlled trial. $N$ Engl J Med 301, 687-690.

34. Moertel CG, Fleming TR, Creagan ET et al. (1985) Highdose vitamin $\mathrm{C}$ versus placebo in the treatment of patients with advanced cancer who have had no prior chemotherapy. A randomized double-blind comparison. $N$ Engl J Med 312, 137-141.

35. Salganik RI (2001) The benefits and hazards of antioxidants: controlling apoptosis and other protective mechanisms in cancer patients and the human population. J Am Coll Nutr 20, 5 Suppl., 464S-467S. 
36. Heaney ML, Gardner JR, Karasavvas N et al. (2008) Vitamin C antagonizes the cytotoxic effects of antineoplastic drugs. Cancer Res 68, 8031-8038.

37. Conner M, Kirk SFL, Cade JE et al. (2001) Why do women use dietary supplements? The use of the theory of planned behaviour to explore beliefs about their use. Soc Sci Med 52, 621-633.

38. Patterson RE, Neuhouser ML, Hedderson MM et al. (2003) Changes in diet, physical activity, and supplement use among adults diagnosed with cancer. J Am Diet Assoc 103, 323-328.

39. Fisher B, Dowding D, Pickett KE et al. (2007) Health promotion at NHS breast cancer screening clinics in the UK. Health Promot Int 22, 137-145.

40. McDavid K, Breslow RA \& Radimer K (2001) Vitamin/ mineral supplementation among cancer survivors: 1987 and 1992 National Health Interview Surveys. Nutr Cancer 41, 29-32.

41. Alamian A, Rouleau I, Simard J et al. (2006) Use of dietary supplements among women at high risk of hereditary breast and ovarian cancer (HBOC) tested for cancer susceptibility. Nutr Cancer 54, 157-165.

42. Seema P, Paul B \& Paolo B (2003) Meta-analysis of social inequality and the risk of cervical cancer. Int J Cancer $\mathbf{1 0 5}$, 687-691.

43. World Health Organization (1990) Diet, Nutrition and the Prevention of Chronic Diseases WHO Technical Report Series no. 797. Geneva: WHO.

44. World Cancer Research Fund \& American Institute for Cancer Research (1997) Food, Nutrition and the Prevention of Cancer: A Global Perspective. Washington, DC: American Institute for Cancer Research.
45. Levine M, Wang Y, Padayatty SJ et al. (2001) A new recommended dietary allowance of vitamin $\mathrm{C}$ for healthy young women. Proc Natl Acad Sci USA 98, 9842-9846.

46. Salganik RI, Albright CD, Rodgers J et al. (2000) Dietary antioxidant depletion: enhancement of tumor apoptosis and inhibition of brain tumor growth in transgenic mice. Carcinogenesis 21, 909-914.

47. Valko M, Rhodes CJ, Moncol J et al. (2006) Free radicals, metals and antioxidants in oxidative stress-induced cancer. Chem Biol Interact 160, 1-40.

48. Cerhan JR, Saag KG, Merlino LA et al. (2003) Antioxidant micronutrients and risk of rheumatoid arthritis in a cohort of older women. Am J Epidemiol 157, 345-354.

49. Block G, Mangels AR, Norkus EP et al. (2001) Ascorbic acid status and subsequent diastolic and systolic blood pressure. Hypertension 37, 261-267.

50. Rock CL, Newman VA, Neuhouser ML et al. (2004) Antioxidant supplement use in cancer survivors and the general population. J Nutr 134, 3194S-3195S

51. The European Food Safety Authority (2004) Opinion of the scientific panel on dietetic products, nutrition and allergies on a request from the commission related to the tolerable upper intake level of vitamin C (L-ascorbic acid, its calcium, potassium and sodium salts and L-ascorbyl-6-palmitate). EPSA J 59, 1-21.

52. Blanchard EB, Scharff L, Schwarz SP et al. (1990) The role of anxiety and depression in the irritable bowel syndrome. Behav Res Ther 28, 401-405.

53. World Cancer Research Fund (2009) Warning on highstrength vitamin supplements. http://www.wcrf-uk.org/ audience/media/press_release.php?recid $=77 \quad$ (accessed November 2009). 